\title{
Perceived burden on Taiwanese chronic patient and their families under population aging and low birth rate: a short review
}

\begin{abstract}
In Taiwan, increased longevity and declining fertility results many challenges. Considering medical resource consumption and changes in family structure, the study aimed at knowing care needs among older adults who had chronic disease requiring lifelong treatment and additional burden on family members who lived with them. Finally, the study finds out that the most important issue for patients with chronic conditions was the need for care from relatives/friends, followed by talk with family/friends, the need to receive medical/social support information, and economic/social support. The burdens on family member involve psychology, physiology and economy. They need various supports from relatives, friends and health care professionals. Finally, several suggestions have been made to improve their quality of life and to reduce unnecessary consumption of resources.
\end{abstract}

Volume 7 Issue I - 2018

Fei-Hui Huang

Department of Marketing and Distribution Management, Taiwan

Correspondence: Fei-Hui Huang, Department of Marketing and Distribution Management, Oriental Institute of Technology, Pan-Chiao, R.O.C., 2206I, Taiwan, Tel 886937524568, Emailfn009@mail.oit.edu.tw

Received: May 18, 2017| Published: January 25, 2018

Keywords: population aging, low birth rate, chronic disease, homecare system, elderly patients

\section{Introduction}

Aging is a hot global topic. By the year 2020, more than 1billion people will be older than 60years. Population aging is under way in some Asian countries primarily due to increased longevity and declining fertility. It results in many challenges, such as medical and family issues. The elderly represent the largest and most active sector of healthcare and medication consumers. ${ }^{1}$ One of the reasons is most of the seniors affected by at least one chronic illness. It leads more than half of healthcare expenditures are related to the treatment of chronic conditions. The increasing burden of chronic illness is a significant challenge. Furthermore, declining birth rates in Asia is raised concerns. Among the Asian countries, Japan has the lowest birth rate, followed by Singapore, South Korea, Republic of China (Taiwan), and Hong Kong. ${ }^{2}$ Traditionally, the obligation for taking care of parents is the responsibility of the children. Therefore, it will increase the burden on families as long as a senior member of the family suffered from a chronic illness.

In Taiwan, the elderly had reached $7 \%$ of total population in 1993 (aging society), and $12 \%$ at the end of 2014.Also, the fertility rate was only 1.16 in 2014. Taiwan's National Development Council predicts the country will achieve aged society status by 2018 , which requires $14 \%$ of the population to be aged 65 or older. By 2025 , the council expects the elderly to exceed the $20 \%$ mark, which will see Taiwan become a super-aged society. These statuses may affect healthcare, medication, and family resources consumptions. A report from National Health Insurance Administration has shown that about $89 \%$ of older adults have a least one chronic condition, and $26 \%$ have at least two. More than $56 \%$ of all healthcare costs are due to chronic conditions. For most people who have chronic conditions, lifelong treatment is needed for their health management. Failure to take their medications regularly as prescribed can be dangerous and even life threatening. Many of elderly people with chronic medical conditions require long-term care, either in the form of home- or communitybased healthcare or nursing home care, and require expanded healthcare services and facilities for assistance with normal daily activities. Many of them prefer to remain in their private residences for as long as possible.

\section{Chronic health care}

Chronic care management is defined as healthcare management within a health facility for people with one or more chronic conditions or those who are at a high risk of contracting a disease. Chronic problems require continuous, long-term monitoring, rather than episodic assessment. Effective chronic care management generally assists patients in obtaining self-care skills to retard the disease progression and includes evidence-based clinical practices, coordinated care across healthcare settings, ready access to behavioral health services that are integrated with primary care, and the usage of community resources to support patients and families.

Most of the aging patients with chronic medical conditions are self-sufficient with a strong desire to age independently in their own homes. ${ }^{4,5}$ Home healthcare is a subset of long-term care and primarily includes skilled nursing in a home setting. This process can be defined as the receipt of assistance or help with at least one activity of daily living (ADL), such as bathing, eating, dressing, walking across a room, and getting in and out of bed, or one instrumental ADL, such as using a telephone, taking medication, handling money, shopping, and preparing meals. Furthermore, patients' stay in their own homes to receive care is both socially and economically beneficial. ${ }^{6}$ Therefore, the aging patients require increasing their autonomy for enabling them to self-manage their lives safely and at reasonable costs and for reducing unnecessary resources expenditures.

Home care is care that allows a person with special needs stay in their home. It might be for people, who are getting older, are chronically ill, recovering from surgery, or disabled. Home care services include personal care (e.g., help with bathing, washing hair or getting dressed), homemaking (e.g., cleaning, yard work and laundry), cooking or delivering meals and health care (e.g., home health aide). Senior patients can get any type of help they want from caregivers or household in their own home. Non-medical home care is a service that 
helps those in need by assisting with ADLs in order to continue living life from the comfort of his or her own home. Home care is a model that can include both professional and informal support networks such as family, neighbors, and friends.

The patient plays an integral role in the management of chronic disease. ${ }^{7}$ A major objective of elderly care for patients staying at home is to facilitate them in maintaining and promoting self-care. Self-care activities are essential ${ }^{8}$ for improving the competence of the elderly in managing their own health conditions independent of institutional care ${ }^{9}$ Self-care is defined as the actives individuals, families, and communities undertake with the intention of enhancing health, preventing disease, limiting illness, and restoring health. ${ }^{10}$ The Department of Health ${ }^{11}$ defines self-care as "the actions people take for themselves, their children and their families to stay fit and maintain good physical and mental health; meet social and psychological needs; prevent illness or accidents; care for minor ailments and long-term conditions; and maintain health and well-being after an acute illness or discharge from hospital". Self-care is a part of daily living. Mobilization of elders' self-care resources can minimize their health problems and enhance health and well-being even if they are suffering from chronic disease, cognitive impairment and functional limitation. ${ }^{12,13}$ It can help the elders become competent participants and managers of their own health conditions, and it can help them stay in their own home. ${ }^{7,13}$ Therefore, self-care is important in chronic care which goals are not to cure but to enhance functional status, minimize distressing symptoms, prolong life through secondary prevention and enhance quality of life. ${ }^{14}$ Also, self-care ability is shown to be crucial as a health resource in older people, and it may be the decisive factor for managing daily life in their own homes. ${ }^{15}$

Self-care is viewed as being interactive with healthcare systems. It can be distinguished between medical self-care (actions concerning medical problems) and health self-care (action aimed at maintaining and improving health). ${ }^{8}$ In medicine, self-care has been associated with the management of treatment and disease and the focus has been on the transfer of responsibility for certain levels of care from healthcare professionals to the patient. Health self-care includes public health, psychology and nursing. In public health, self-care has been related to economy, Behavior, lifestyle change and support from social systems. ${ }^{7}$ It may be improved for patients by health education services. In psychology, self-care has been linked to internal factors of health ${ }^{16,17}$ and integrated with concepts such as self-concept, health belief and cognitive behavior. In nursing, a practice of activities that individuals initiate and perform on their own behalf is in maintaining life, health and well-being. Individual person or patient to families and communities in collaboration with healthcare professional and healthcare system are involved in self-care. The factors with strong relationships with self-care include health status, overall health beliefs, ${ }^{18}$ activity level ${ }^{19}$ and life satisfaction..$^{20}$

By reducing face-to-face consultations and shortening hospital stays, home care technology can help to compensate for inadequacies in healthcare resources while maintaining or improving care quality. ${ }^{14}$ Moreover, Tele health care has the potential to enable the elderly to remain in a familiar environment close to family and friends and to increase well-being. Such a measure is designed to reduce anxiety ${ }^{6}$ while enabling such residents to manage self-care at home for a longer time. Also, an increasing number of tools such as websites and smart phone applications have been designed to help individuals manage their own healthcare. These achievements in personal healthcare and tools for such can highlight trends and subtle changes to empower patients and improve patient-doctor communication.

\section{Burden on chronic patient and their families}

In Taiwan, increased longevity and declining fertility results many challenges. It leads more than $56 \%$ of all healthcare costs are due to chronic conditions and the average family size is dropped to 3.2 people. Most seniors with chronic medical conditions are selfsufficient with a strong desire to stay in their own homes. They want to live with children (63.3\%), followed by living with spouse $(20.6 \%)$ and living along $(11.1 \%){ }^{21}$

\section{Chronic patient needs}

For the senior patients, they need psychology health care most. Most of them prefer to be cared by their family members or friends and talk with them via a directly way, e.g., face to face and phone call. The senior patients in situations that were less likely to increase the burden on family and friends tended to prioritize the need for care from relatives and friends. ${ }^{22}$ Once the family members have taking time to talk with and care about senior patient, their satisfaction of life work and rest, medication reminder and psychology may be promoted. Otherwise, they may need more medical services to reduce their pressure and excessive dependence on relatives or friends. Senior patients also need assistance on their medical self-care and public health care for having good well-being and life quality. They tend to rely on the support from government or society resources, e.g., Medicaid, elderly annuity, and living allowance, rather than from family resources. In addition, some of patients need to receive more medical information from health care professionals, TV media, or family. Enhancing patient's satisfaction of medical services, their satisfaction of life work and rest and care need may be promoted. It shows that the government should pay attention to provide related educational service for all patients to enjoy related benefits. In contrast, senior patient without good life work and rest or economic capacity, they may need more assistance, e.g., medication reminders. ${ }^{23}$ It is because taking medication regularly as prescribed was a challenge for some senior patients. Especially patients aged 80 years or more, they may be affected by memory degradation or multiple chronic diseases to require a tool to serve as a reminder and assist them in taking the correct long-term medication at the correct time. Huang ${ }^{24}$ suggested that a user-centered design of mediation reminder product should include reminder design, mobile medication reminder, and ease of use, flexible design, and modular Design.

\section{Burden on their family members}

The biggest pressure for the family member of chronic patient is from psychology, followed by physiology and economy. Family member with psychological pressure may enhance the needs of psychological support and support from social systems and reduce their life satisfaction, especially for the families caring a senior patient with emotionally unstable. Moreover, families with economic burden may enhance their psychological needs and reduce their life satisfaction. Most of families need support from relatives and friends and receiving more information of society services and assisting tool of medication reminders for reminding senior patient taking the right drugs at the right time to reducing their pressure. There still have some difference needs for difference families. These are described as following,

i. For family member who has to care senior patient with multiple chronic conditions: they need more diseases information from healthcare professionals and support from social systems.

ii. For family member who has to care more than one senior patient: 
they need more information of medical services, supports from relatives or friends and social systems, economy support and their own time.

iii. For female caregivers: They need to learn more information about the right way to care the patient and the foods that the patient may or may not eat.

iv. For male caregivers: they tend to believe in medical services.

v. For the families with higher education: they need more contact with their relatives or friends.

vi. For the married families: they need more support from social systems then single families because the married families have to care themselves, children and seniors at the same time.

\section{Conclusion}

Population aging is under way in Taiwan due to increased longevity and declining fertility. It also leads a change on the family structure and family size. Nowadays, the average family size of Taiwan is 3.2people. This study is to understand the needs of senior patient with chronic medical conditions for living in the home environment and the burden on the family member of senior patient under the situation of increasing the proportion of chronic patients and reducing the proportion of family members. Here, psychological support from relatives and friends has been point out as the most important need for most of senior patients and family members. Most of them prefer to contact with relatives and friends in person or by phone. We suggest that patients and family members should be encouraged to have a good family relationship and social life. Medical information from health professionals or staffs by a phone call or internet is also important for patients and their families. But, most health staffs do not take the initiative to inform information. For meeting people needs in receiving useful information, providing messaging services to notify them related information in real time is suggested. Finally, providing health education services is suggested for senior patients and their families learning more self-care or care knowledge. For family members, one of the most important factors may affect their life satisfaction is economic burden. Educational services may provide information about elderly annuity, living allowance and social support to them. Even though the factor of psychological support from families can reduce such pressure, it still a topic for more investigation in reducing the economic burden in the near further.

\section{Conflict of Interest}

None

\section{Acknowledgement}

The authors would like to express their gratitude to National Science Council of Taiwan for the funding under the grant number NSC 101-2221-E-161 -002.

\section{Funding}

None.

\section{References}

1. Steinman M, Hanlon J. Managing medications in clinically complex elders: There's got to be a happy medium. JAMA. 2010;304(14):1592-1601.

2. Central Intelligence Agency (CIA) The world factbook. Country comparison: Birth rate.
3. Taiwan's National Development Council. Taiwan: Population Projections for Republic of China. 2014

4. Bodenheimer T, Lorig K, Holman H, et al. Patient self-management of chronic disease in primary care. JAMA. 2002;288(19):2469-2475.

5. Costa D. A house of her own: old age assistance and living arrangements of older non-married women. Journal of Public Economics. 1999;72:39-60.

6. McGarry K, Schoeni R. Social security, economic growth, and the rise in elderly widows' independence in the twentieth century. Demography. 2000;37(2):221-236.

7. Lorensen M, Holter IM, Evers GC, et al. Cross-cultural testing of the "appraisal of self-care agency: ASA scale" in Norway. Int J Nurs Stud. $1993 ; 30(1): 15-23$

8. Vickery DM, Iverson DC. Medical self-care and use of the medical care system. USA: In Health Promotion in the Workplace. 1997;367-389.

9. Lee H, Manns B, Taub K, et al. Cost analysis of ongoing care of patients with end-stage renal disease: The impact of dialysis modality and dialysis access. Am J Kidney Dis. 2002;40(3):611-622.

10. World Health Organization (WHO). Health education in self-care: possibilities and limitations. Switzerland: Report of a Scientific Consultation. 1984

11. Department of Health. Self care: a real choice. London: Department of Health. 2005.

12. Gadow S. Frailty and strength: the dialectic in aging. Gerontologist. 1983;23(2):144-147

13. Ruffing-Rahal MA. Rationale and design for health promotion with older adults. Public Health Nurs. 1991;8(4):258-263.

14. Grumbach K. Chronic illness, comorbidities, and the need for medical generalism. Ann Fam Med. 2003;1(1):4-7.

15. Hoy B, Wagner L, Hall EO. Self-care as a health resource of elders: An integrative review of the concept. Scand J Caring Sci. 2007;21(4):456466

16. Hampson SE, Glasgow RE, Toobert DJ. Personal models of diabetes and their relations to self-care activities. Health Psychol. 1990;9(5):632-646.

17. Penning MJ, Keating NC. Self-informal and formal care: partnerships in community-based and residential long-term care settings. Can J Aging 2000;19(S1):75-100.

18. Klainin P, Ouannapiruk L. A meta-analysis of self-care behavior research on elders in Thailand: an update. Nurs Sci Q. 2010;23(2):156-163.

19. Harrison EL, Fisher KL, Lawson JA, et al. Exploring the role of housing type on physical activity and health status in community-dwelling older adults. Activities Adapt Aging. 2010;34(2):98-114.

20. Borg G, Hallberg IR, Blomquist K. Life satisfaction among older people $(65+)$ with reduced self-care capacity: the relationship to social, health and financial aspects. J Clin Nurs. 2006;15(5):607-618.

21. Ministry of health and welfare. Taiwan's elderly living analysis. 2013.

22. Huang FH. Self-care needs of seniors with chronic medical conditions for living in their own homes. Home Health Care Management \& Practice. 2016;28(2):109-114.

23. Huang FH. Explore home care needs and satisfaction for elderly people with chronic disease and their family members. Procedia Manufacturing. 2015;3:173-179.

24. Huang FH. The needs of smart medication reminder for elderly people with chronic conditions, In Proceedings of 5thInternational Conference on Applied Human Factors and Ergonomics AHFE 2014, Kraków, Poland. In Advances in Human Aspects of Healthcare. 2014;417-426. 